\title{
ScIDoC
}

International Journal of Pediatric Health Care \& Advancements (IJPA) ISSN 2572-7354

\section{A Rare Case of 10-year-old Child with Multisystem Inflammatory Syndrome (MIS-C)}

Case Study

Ashish Goti ${ }^{1 *}$, Ramesh Dihora ${ }^{2}$, Zankhan Mirani ${ }^{3}$, Manthan Mirani ${ }^{4}$

${ }^{1}$ MBBS, DCH, Consultant Neonatologist and Pediatric Intensivist at NICE Children Hospital, Surat, India.

${ }^{2}$ MBBS, MD, Fellowship in Neonatology (IAP), Consultant Neonatologist, at NICE Children Hospital, Surat, India.

${ }^{3}$ MBBS, Medical Officer at NICE Children Hospital, Surat, India.

${ }^{4}$ MBBS, Medical officer at NICE Children Hospital, Surat, India.

\section{Abstract}

\begin{abstract}
10-year-old male presented with 5 days of fever accompanied with cough, vomiting, muscle weakness, conjunctival injection, tachycardia and pharyngeal erythema alert but having toxic look. Detailed laboratory investigations revealed MIS-C with no covid contact history and RT PCR were negative. Dobutamine and methylprednisolone led to improved therapeutic outcome.
\end{abstract}

Keywords: MIS-C; Pediatric Patient; Post Covid Illness.

\section{Introduction}

The corona virus disease 2019 (Covid-19) pandemic has caused catastrophic disease worldwide. Children and infants have been relatively spared from severe COVID-19, with pediatric cases accounting for less than $2 \%$ of COVID hospitalizations. The U.S. Centre for Disease Control and Prevention (CDC) recently recognized a new syndrome in children and teens ages $2-15$ that is associated with the coronavirus that causes COVID-19. While the syndrome is very rare, it can be dangerous. Multisystem inflammatory syndrome in children(MIS-C) was first identified in April 2020, by doctors at children's hospitals in the United States and the United Kingdom. The condition has also been called pediatric inflammatory multisystem syndrome(PIMS) $[1,2]$. No such case has been reported from India till date. Here we report first case of MIS-C in paediatric patients from India.

\section{Case Study}

A 10-year-old previously healthy boy was presented with feverfor5 days with symptoms of cough, abdominal pain, vomiting, rash and conjunctivitis, fatigue and irritability. Vital parameters showed temperature $102.3^{\circ} \mathrm{F}, \mathrm{SpO}_{2}-98 \%$, Respirations-24/min and Heartrate- $136 / \mathrm{min}$. Physical examination demonstrated conjunctival redness, oedema, moist mucous membranes with pharyngeal erythema without exudates, respiratory system clear to auscultation bilaterally, cardiovascular system: S1, S2 normal but tachycardia, abdomen was soft and non-tender (figure 1). Investigations revealed raised WBC count 9800 (Neutrophils-81, Lymphocytes-10, Eosinophils-4, Monocytes-4, Basophils-1)with haemoglobin $11.5 \mathrm{~g} /$ dland platelet count 1.66 lakhs. No covid positive contact history and X-ray chest was normal. A negative result was obtained for rapid antigen test for covid 19. Patient was admitted and every two hourly temperature was recorded. The patient continued to have spiking fever every 4-6 hours and tachycardia. Sleeping heart rate was $126 \mathrm{bpm}$ without fever. The patient developed loose motion and abdominal pain. Preliminary diagnosis of patient lead to initial treatment of patient with therapyfor mitigating viral infection using a moxicillin + clavulanic acid and Paracetamol accompanied with IV fluids(0.45\% Dextrose with $\mathrm{K}+@ 1 \mathrm{mEq} / \mathrm{kg} /$ day). Vitamin C, Zinc and Vitamin $\mathrm{D}$ Supplementation were also given to patient treat fatigue but unfortunately there was no significant improvement observed in the condition of patient.

Due to persistent high-grade fever $\left(102.4^{\circ} \mathrm{F}\right)$ and tachycardia(146 $\mathrm{bpm})$, the patient was shifted to paediatric ICU. Repeat investigations showed $\mathrm{Hb} 10.5 \mathrm{gm} \%$, Asignificant rise in TLC count (13000), neutrophils-80\%, lymphocyte- $11 \%$, eosinophil- $4 \%$, monocyte-4\%, basophils-1\%), platelet 142000, CRP level(106.80

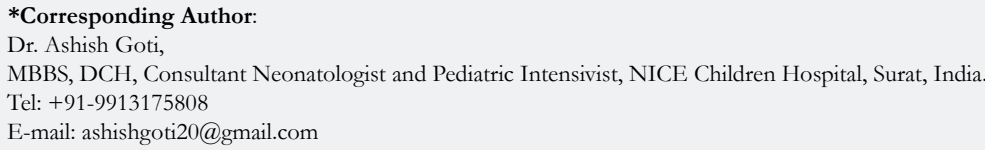

Citation: Ashish Goti, Ramesh Dihora, Zankhan Mirani, Manthan Mirani. A Rare Case of 10-year-old Child with Multisystem Inflammatory Syndrome (MIS-C). Int J Pediat Health Care Adv.. 2020;6(1):99-100. doi: http://dx.doi.org/10.19070/2572-7354-2000028

Copyright: Ashish Goti ${ }^{\circ} 2020$. This is an open-access article distributed under the terms of the Creative Commons Attribution License, which permits unrestricted use, distribution and reproduction in any medium, provided the original author and source are credited. 
Figure 1. Clinical presentation of the MIS -C.

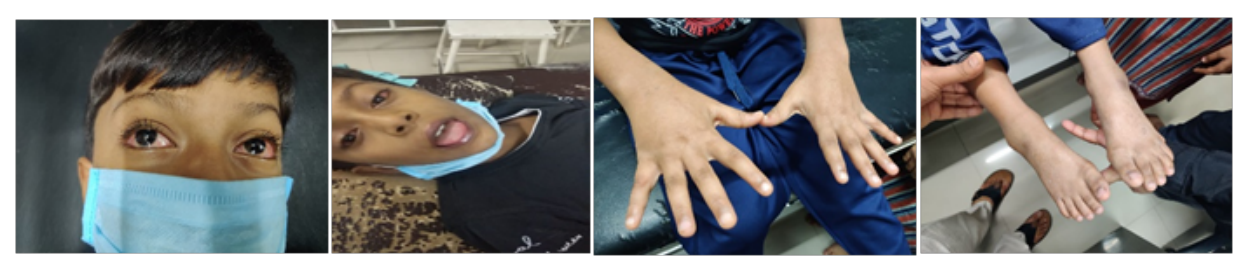

$\mathrm{mg} / \mathrm{dl})$, D-dimer(1.2 mg/dl) andferritin(284.82 ng/dl) was observed on 7 th day of initial fever. Peripheral smear-negative for malarial parasite. The initial treatment was discontinued due to sever tachycardia (151bpm) and hypotension (76/50). 2D echo of the patient showed poor myocardial function(EF 30\%). $\mathrm{Pa}-$ tient was shifted to dobutamine therapy and suspected for MIS$\mathrm{C}$ due to constant hypotension and decrease cardiac function. Hence immediately patient was tested for CovidIgG test which showed a positive result. The absence of preceding symptoms of COVID-19 indicated by negative polymerase chain reaction result with positive antibody test confirmed MIS-C. Immediately the patient was shifted on MIS-C therapy starting with IVIG(2g/ $\mathrm{kg}$ ), methylprednisolone $\left(30 \mathrm{mg} / \mathrm{m}^{2} /\right.$ day), aspirin $(6-\mathrm{mg} / \mathrm{kg} / \mathrm{day})$, pantoprazole $(40 \mathrm{mg} /$ day $)$ and ceftriaxone $(75 \mathrm{mg} / \mathrm{kg}$ IV)treatment.

Following the first dose of treatment congestion subsided along with improved heart function ( $\mathrm{EF} 45 \%$ ) with reduction in fever. On three days of continued treatment patient was shifted to paediatric wardprescribed with oral prednisolone therapy. The patient was discharged from the hospital on the $7^{\text {th }}$ day of admission. The vital parameters of the patient were normal on discharge and the patient showed no symptoms on regular follow-up for two weeks.

\section{Discussion}

MIS-C or PIMS has features in common with toxic shock syndrome and an illness called Kawasaki disease, which cause inflammation of the blood vessels throughout the body. The association with this syndrome and COVID-19 may be due to the body's immune response to the presence of the SARS-CoV-2. Persistent symptoms of conjunctival redness, pharyngeal erythema with prolonged fever and chillitis, rash, myocarditis, elevated C-reactive protein level supported by IgG Antibody testrevealed confirmation of MIS-C infectionin patient with prior infection due to
COVID-19 virus which was in contrast to Kawasaki Disease [1]. The distinct symptoms demonstrating cardiac dysfunction or depression, coagulopathy, gastrointestinal symptoms accompanied by mild respiratory symptoms and occasional indications for supplemental oxygen was characteristic of MIS-C which was found to be a contrasting with most cases of acute Covid-19 among hospitalized children [2] and no complications related to circulatory failure in acute phase, artery aneurysm or resistance to intravenous immunoglobulin were observed as in Kawasaki Disease [3]. Diffuse myocardial edema and hyperaemia without evidences of focal myocardial necrosis which was in contrast to recent publications of myocarditis associated with COVID-19 [4] followed by treatment with IVIG, glucocorticoids, and vasopressors as immediate functional therapy was in consistent with other studies published [5]. Early diagnosis of cardiac and gastrointestinal symptoms followed by serial measurement of cardiac function with prompt treatment acts as a key to prevent multi-organ failure and long term organ damage due to MIS-C.

\section{References}

[1]. Rivera-Figueroa A, Santos R, Simpson S, Garg P. Incomplete Kawasaki disease in a child with Covid-19. Indian Pediatr. 2020; 57(7): 680-681. PMID: 32393680.

[2]. Dong Y, Mo X, Hu Y, Qi X, Jiang F, Jiang Z, Tong S, et al. Epidemiology of COVID-19 among children in China. Pediatrics. 2020; 145(6): e20200702. PMID: 32179660

[3]. Gatterre P, Oualha M, Dupic L, Iserin F, Bodemer C, Lesage F, et al. Kawasaki disease: An unexpected etiology of shock and multiple organ dysfunction syndrome. Intensive Care Med. 2012; 38: 872-8. PMID: 22273753. https://pubmed.ncbi.nlm.nih.gov/22273753/

[4]. Inciardi RM, Lupi L, Zaccone G, Italia L, Raffo M, Tomasoni D, et al. Cardiac involvement in a patient with coronavirus disease 2019 (covid-19). JAMA Cardiol. 2020; 5(7): 819-824. PMID: 32219357.

[5]. Verdoni L, Mazza A, Gervasoni A, Martelli L, Ruggeri M, Ciuffreda M, et al. An outbreak of severe Kawasaki-like disease at the Italian epicentre of the SARS-CoV-2 epidemic: an observational cohort study. Lancet. 2020; 395: $1771-1778$ 